\section{Linking Program Review to External Scrutiny: International Developments}

\section{Elaine El-Khawas}

Elaine El-Khawas is professor of higher education at the University of California at Los Angeles. Address: School of Education, Moore Hall, UCLA, Los Angeles, CA 90095 USA.

$\mathrm{P}$ rogram review is in part an administrative procedure, a series of steps that many universities take in order to review and improve their academic programs. However, it also has a major symbolic importance, serving as an illustration of the way that academics govern themselves. In the traditional version of program review, academics take responsibility for defining issues, gathering evidence, and coming to a judgment about the strengths and weaknesses of an academic program or department. This process exemplifies many values important to academics: encouraging responsible participation of the professoriate in university governance processes; determining matters of educational quality at the departmental level — the "basic unit" of the academic hierarchy; and, most importantly, recognizing the primacy of academic authority on educational matters.

Over time, these processes have gained wide credibility, both within the academic and scholarly community and with external regulatory and funding bodies. In the United States, most universities and colleges make use of program review, with most public universities implementing a five-year rolling cycle for review of all academic departments. ${ }^{1}$ Similarly, professional licensing bodies in many countries now rely on program review as an element in their recognition process for educational programs.

\section{A recent estimate is that there are cur- rently more than 70 quality assessment agencies around the world.}

Several recent developments suggest that, in many countries, program review is being expected to take on a new role-as a key component of the quality assessments carried out by governmental and other external agencies. A recent estimate is that there are currently more than 70 quality assessment agencies around the world. In response, new forms of university scrutiny have appeared in England, in continental Europe, and in other countries during the 1980s and 1990s, reflecting concerns about accountability to the public, adequate mechanisms of "quality assurance," or "value for money."

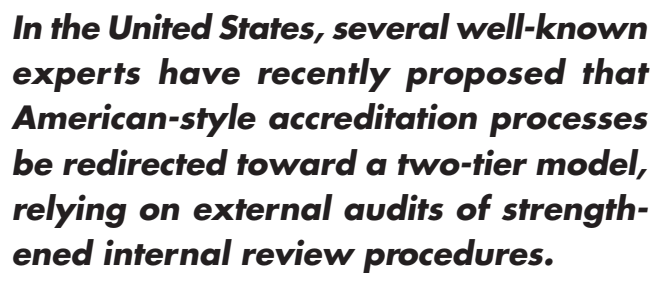

In the United States, several well-known experts have recently proposed that American-style accreditation processes be redirected toward a two-tier model, relying on external audits of strengthened internal review procedures.

As policy officials in most industrialized countries have sought to develop stronger assessment mechanisms, traditional program review processes are being held to standards of new accountability. In fact, in many countries, a policy consensus appears to be emerging in support of a two-tier model for quality assurance. This model relies on a balance of external and internal procedures: state agencies act as coordinators of quality assurance but then rely on substantial work within academic institutions to assemble required data and interpret results. Thus, for example, in Sweden, the 1993 Reform Act, subtitled "Freedom for Quality," accords greater autonomy to universities while charging the national agency with auditing the quality assurance processes that operate within the universities. In the United States, several wellknown experts have recently proposed that American-style accreditation processes be redirected toward a two-tier model, relying on external audits of strengthened internal review procedures. In many European countries, program reviews have seen growing use, both as voluntary measures adopted by university rectors and as part of countrywide efforts to implement new processes of quality assurance. In the United Kingdom, it has been proposed that the new Quality Assurance Agency foster a better "harmonization" of internal and external review arrangements.

For government, the two-tier approach, relying on internal review procedures, offers an economical model-requiring far less time and resources to implement than governmentally directed approaches to quality assurance and, more pragmatically, is preferable to the use of new, externally developed mechanisms.

As the process evolves, important questions are at stake: will program review be compromised as it becomes part of government scrutiny into questions about the quality, efficiency and productivity of academic programs? Might this trend presage a more subtle form of 
external control? Current procedures that link both internal and external review requirements might prove to be a transitional phase, where internal review was weakened as it was adapted to serve external purposes. A different outcome is also possible: the internal review process could gain greater credibility and value in its new form, successfully adapting academically developed procedures to the new trend toward external accountability. Thus, the current reliance on traditional academic forms of self-regulation could eventually result in a lessening of governmental zeal to control, a willingness to let academics conduct their own business according to their own norms and values.

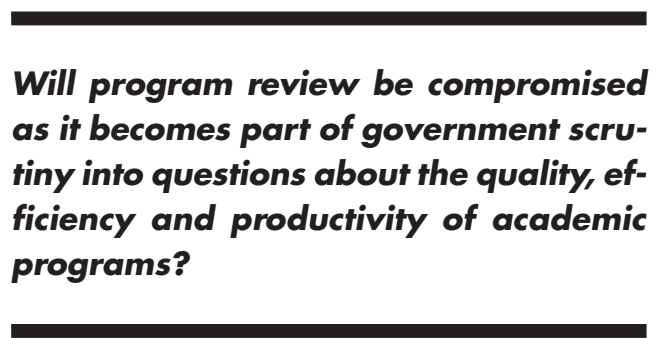

These questions are yet to be resolved, but the use of internal review processes to serve external audiences can be expected to continue to serve as an arena for this conflict between government and academics over who controls the monitoring and evaluation of academic programs and decisions. An analysis of recent experience provides initial evidence that program review can change in important ways as it becomes more closely linked to governmental systems of quality assurance. The content of the review changes, especially to consider topics that are specified by external agencies, as the governance process changes, as departments and deans have less direction in setting procedures, and as new elements are introduced to satisfy additional concerns of external parties.

Such "two-tier" arrangements should be watched carefully. Hopefully conflicting values can be identified, debated, and resolved. The objective should be to recognize that, in addition to the accountability purposes that governments must pursue, internal review still holds a significant potential value for stimulating internal improvement in colleges and universities.

\section{Notes}

1. John Brennan, Elaine El-Khawas, and Tarla Shah, Peer Review and the Assessment of Higher Education Quality: An International Perspective Quality Support Centre, Report no. 3 (London: Open University, 1994).

\section{The International Responsibilities of the College President}

\section{Robert A. Scott}

Robert A. Scott is president of Ramapo College of New Jersey. 505 Ramapo Valley Rd., Mahwah, NJ 07430, USA. Fax: (201) 529-6737.

$\mathrm{T}$ he college and university president in the United States fills many roles. He or she serves as salesman, lobbyist, educator, philosopher, cheerleader, and corporate executive. All too often, presidents fill these roles without a sense of the larger context in which they operate. They, too, must think globally even as they act locally in serving as academic presidents.

Our students will graduate and likely supervise or be supervised by someone of a different ethnic, national, racial, or religious group. Their neighbors will represent these different groups. Sources of institutional revenues are now multinational; even states have set up international trade offices with priorities for local investment. More students should study in other countries in order to benefit from the cross-cultural fertilization of ideas and be prepared for careers and citizenship in the next century.

Finally, organizational issues in colleges and universities are quite similar worldwide, and we can learn from discussing these issues with academic leaders in other national settings. While the issues of governance, student preparation, resource development, technology investment, and curriculum are similar internationally, local traditions and circumstances dictate different responses. By comparing information globally, we can improve our strategies locally.

\section{Our students will graduate and likely supervise or be supervised by someone of a different ethnic, national, racial, or religious group.}

I have been fortunate in my presidency to be involved in several activities that have helped me develop these cross-cultural perspectives. As a member of the American Council on Education-Council of European Rectors Trans-Atlantic "Dialogue," I have been able to participate in cross-cultural discussions about planning, governance, curriculum, and finances. With University Mobility Asia Pacific and UNESCO, I have been able 